\title{
Follow-up care delivery in community-based hypertension and type 2 diabetes management: a multi-centre, survey study among rural primary care physicians in China
}

\author{
Yi Wang ${ }^{1 \dagger}$, Xiu-Jing Hu ${ }^{1,2+}$, Harry H. X. Wang ${ }^{1,3^{*}}$, Hong-Yan Duan ${ }^{4}$, Ying Chen ${ }^{5}$, Yu-Ting Li ${ }^{6}$, Zi-Lin Luo ${ }^{1,7}$, Xin Li ${ }^{8}$,
} Jia-Ji Wang ${ }^{9,10}$ and Stewart W. Mercer ${ }^{11}$

\begin{abstract}
Background: Follow-up care is crucial but challenging for disease management particularly in rural areas with limited healthcare resources and clinical capacity, yet few studies have been conducted from the perspective of rural primary care physicians (PCPs). We assessed the frequency of follow-up care delivered by rural PCPs for hypertension and type 2 diabetes - the two most common long-term conditions.

Methods: We conducted a multi-centre, self-administered survey study built upon existing general practice course programmes for rural PCPs in four provinces. Information on follow-up care delivery were collected from rural PCPs attending centralised in-class teaching sessions using a set of close-ended, multiple choice questions. Binary logistic regression analysis was performed to examine physician-level factors associated with non-attainment of the target frequency of follow-up care for hypertension and type 2 diabetes, respectively. The final sample consisted of rural PCPs from 52 township-level regions. The Complex Samples module was used in the statistical analysis to account for the multistage sample design.

Results: The overall response rate was $91.4 \%$. Around one fifth of PCPs in rural practices did not achieve the target frequency of follow-up care delivery (18.7\% for hypertension; $21.6 \%$ for type 2 diabetes). Higher education level of physicians, increased volume of daily patients seen, and no provision of home visits were risk factors for non-attainment of the target frequency of follow-up care for both conditions. Moreover, village physicians with less working experiences tended to have less frequent follow-up care delivery in type 2 diabetes management.

Conclusions: Efforts that are solely devoted to enhancing rural physicians' education may not directly translate into strong motivation and active commitment to service provision given the possible existence of clinical inertia and workload-related factors. Risk factors identified for target non-attainment in the follow-up care delivery may provide areas for capacity building programmes in rural primary care practice.
\end{abstract}

Keywords: Follow-up care delivery, Hypertension, Type 2 diabetes, Treatment goal, Target non-attainment, Rural area, Primary care physicians

*Correspondence: haoxiangwang@163.com; haoxiangwang@cuhk.edu.hk

${ }^{\dagger}$ Yi Wang and Xiu-Jing Hu contributed equally to this work.

1 School of Public Health, Sun Yat-Sen University, No.74 Zhongshan Road

2, Guangzhou 510080, People's Republic of China

Full list of author information is available at the end of the article

\section{Introduction}

As the major preventable risk factors for cardiovascular disease (CVD) and premature death, hypertension and type 2 diabetes present long-lasting challenges to global 
public health as reflected by the enormous burden of morbidity and disability [1-3]. Along with the improved life expectancy and epidemiological transition, the rise in the number of adults with elevated blood pressure (BP) is now occurring largely in low and middle-income countries (LMICs) [4, 5]. Meanwhile, the prevalence of type 2 diabetes is also rising rapidly across LMICs, particularly in rural regions, and is associated with increased risk of all-cause mortality [6, 7].

Like many other developing countries, China is facing challenges with the awareness, treatment and control of long-term conditions such as hypertension and type 2 diabetes in rural areas $[8,9]$. A highlight of national efforts to address healthcare gaps in China is the delivery of basic public health (BPH) service in primary care settings underpinned by government investment at both national and local levels to strengthen preventive health care $[10,11]$. In rural regions, those who have completed nationally-accredited medical study curriculum at secondary education level or above are eligible for working as village physicians. The government statistics shows that most village physicians $(93.4 \%)$ in China did not complete tertiary education (i.e., without a college or undergraduate degree) as of 2018 [12]. They work at village clinics and countryside infirmaries, serving as routine primary care physicians (PCPs) to deliver $\mathrm{BPH}$ preventive care in parallel with essential medical care in rural areas. The health management of hypertension and type 2 diabetes are free-of-charge items included as part of the BPH service package to enhance the capacity building for community-based disease prevention and health promotion that are responsive to community healthcare needs.

In the context of the nationwide BPH service provision, the follow-up care for hypertension and type 2 diabetes including general assessment of overall health, recommendations on lifestyles, and review of medical regime are indispensable for improving population health in primary care [13]. A substantial body of international evidence strongly suggests that primary care is one of the most cost-effective strategies for reducing morbidity, disability, and premature mortality attributed to longterm conditions $[14,15]$. Meanwhile, existing literature also suggests that patient education and skill building could serve as facilitators to good patient adherence in hypertension and diabetes management for attaining the treatment goals $[16,17]$. This would require enhanced patient-physician interactions built upon physicians' capabilities to deliver a broad scope of person- and family-centred care to achieve desired health outcomes in the community. Rural areas, however, are likely to be subject to poor availability of healthcare resources and limited clinical capacity of village physicians. This may serve as a major obstacle to supporting regular delivery of community-based continuous care for rural populations.

A recommended frequency of 4 times per year for follow-up care delivery has been suggested in the recent Chinese national standards (3rd edition) for delivering $\mathrm{BPH}$ service in people diagnosed with hypertension or type 2 diabetes [18]. Nevertheless, little is known thus far about frontline physicians' adherence to this recommended practice in the routine provision of rural primary care. International studies also demonstrate the possibility that education of rural health workforce does not always confer sustained effects in active commitment of physicians to rural community practice [19-21]. This would require more investigation and evidence. The main objective of this study was to assess the frequency of follow-up care delivered by rural PCPs for hypertension and type 2 diabetes - the two most commonly seen long-term conditions. We tested the hypothesis that physician-level factors, in particular the physician's education level, were associated with non-attainment of the target frequency of follow-up care for both hypertension and type 2 diabetes in the study.

\section{Methods \\ Study design}

This was a multi-centre, survey study built upon existing course programmes on general practice (GP) education and training for rural primary care physicians (PCPs) in four provinces in China. In Yunnan and Guizhou provinces (western China), and Henan province (central China), a theoretical-practical training programme with centralised in-class teaching sessions was launched by the Chinese General Practice Young Professionals Alliance in 2019. This was partnered with the Chinese Medical Association to enrol PCPs in rural clinical practice for continuing medical education. Meanwhile in Guangdong province (southern China), a GP Professional Boost-up Training Programme was concurrently launched by the Guangdong Primary Healthcare Association (GDPHA) [22] - an officially registered body responsible for developing education and training that encompass the full scope of primary care. The Programme was established in conjunction with the Guangdong Health Commission to enhance the healthcare capacity of PCPs in rural areas where the Gross Domestic Product per capita falls below the national average.

\section{Setting and data source}

The survey study was conducted on the sites where centralised in-class teaching sessions were held in each province. A set of close-ended, multiple choice questions drawn from literature review were used to gather selfreport information from village physicians. The content 
validity of the survey was assessed by an expert panel consisting of two epidemiologists (YW and YC), two public health professionals (HHXW and YTL), and two GP consultants (HYD and JJW) who reviewed each item with regard to the relevancy and clarity. A pilot study was conducted among a systematic sample of 12 rural PCPs. The purpose of the project was introduced by the course instructor and questionnaires were disseminated to eligible class attendees by the on-site teaching assistant at the beginning of the course session. Participants were guided to return the anonymous, self-administered questionnaires to the course instructor during the session break. All the original questionnaires, upon the on-site check for completeness and correctness, were sent by postal mail to the study coordinating centre at Sun Yat-Sen University.

\section{Participants}

We aimed to recruit at least $80 \%$ of rural PCPs fulfilling the eligibility criteria from centralised in-class teaching sessions, and a minimum of 120 PCPs were anticipated in each of the four provinces. The criteria of target subjects were those who 1 ) worked as rural primary care clinicians affiliated with village clinics or countryside infirmaries; 2 ) had class attendance on the day of data collection; and 3) practicing community-based follow-up care for hypertension and type 2 diabetes on a regular basis. Those who practiced chronic disease management in primary care for less than 12 months were excluded. The data collection was completed in August 2019 and the final sample consisted of rural PCPs from 52 township-level administrative regions.

\section{Study variables and measurements}

We collected anonymous data on age, gender, ethnics, education level, years of GP working experiences, number of patients seen per day, physician-perceived healthcare needs, services delivered on chronic disease management, and settings and frequencies of follow-up care for hypertension and type 2 diabetes. In this study, we referred to the recent national standards for Basic Public Health Services (3rd edition) in China, where a frequency of 4 times per year for follow-up care delivery has been set as a recommended target in the hypertension and type 2 diabetes management [18].

\section{Statistical analysis}

Two trained medical students independently entered the data with double entry verification in EpiData 3.1 (Denmark). Statistics with standard error (SE) or 95\% confidence interval (CI), where appropriate, were applied in descriptive analysis. We conducted binary logistic regression analysis to examine physician-level factors associated with non-attainment of the target frequency of follow-up care for hypertension and type 2 diabetes, respectively, after controlling for confounders. A 20:1 rule was used for regression analysis where a minimum number of 400 participants was conservatively required for a regression model consisting of up to 20 independent predictor categories. A $p$ value $<0.05$ was considered statistically significant. All statistical analyses were done in IBM SPSS Statistics 25 (Chicago, IL, USA) and the Complex Samples module was used to account for the multistage sample design.

\section{Ethical consideration}

Informed consent was obtained from all participants in the study. Data anonymisation was performed by removing subject identifiers from the dataset prior to data analysis. Ethics approval was granted from the School of Public Health Biomedical Research Ethics Review Committee at Sun Yat-Sen University (Ref: SYSUSPH2019032) in accordance with the Declaration of Helsinki 2013.

\section{Results}

\section{Characteristics of survey participants}

A total of 602 rural PCPs responded to the survey, with an overall response rate of $91.4 \%$. No significant differences existed in the response rates at each study site. The mean age of survey respondents was 38.6 (SE 0.5) years, with one fifth of subjects aged 50 years and above. Male and female physicians accounted for an approximately equal proportion ( $51.5 \%$ vs $48.5 \%$ ). More than one third (40.4\%) of physicians were ethnic minorities. Slightly over half (53.3\%) of participants had more than ten years of practicing primary care in rural areas. Nearly one third (30.6\%) of survey participants had routine clinical encounters with over 20 patients per day. Over two thirds $(71.8 \%$ [432/602]) of village physicians did not complete an undergraduate education. In general, survey participants with undergraduate education or above were younger $(p<0.001)$ and had shorter length of years in practicing primary care than their counterparts with lower education level $(p<0.001)$ (Table 1$)$.

\section{Frequency and venue of follow-up care for hypertension and type 2 diabetes}

Around one fifth of village physicians did not achieve the target frequency of follow-up care for hypertension and type 2 diabetes in the study. They reported a follow-up frequency of less than 4 times per year for hypertension $(18.7 \%)$ and type 2 diabetes (21.6\%), respectively. The majority of rural PCPs performed follow-up care through mixed clinic-based consultations and home visits, albeit a small proportion (17.6\% for hypertension; $18.3 \%$ for type 
Table 1 Characteristics of survey participants

\begin{tabular}{|c|c|c|c|c|}
\hline Variables & Total $(N=602)$ & Below undergraduate $(n=432)$ & $\begin{array}{l}\text { Undergraduate or above } \\
(n=170)\end{array}$ & $P$ value \\
\hline Age, years & $38.6(0.5)$ & $39.6(0.6)$ & $35.9(0.7)$ & $<0.001$ \\
\hline \multicolumn{5}{|l|}{ Age, groups } \\
\hline$<30$ years & $139(23.1)$ & $103(23.8)$ & $36(21.2)$ & \multirow[t]{4}{*}{$<0.001$} \\
\hline 30-39years & $164(27.2)$ & $82(19.0)$ & $82(48.2)$ & \\
\hline 40-49years & $178(29.6)$ & $144(33.3)$ & $34(20.0)$ & \\
\hline$\geq 50$ years & $121(20.1)$ & $103(23.8)$ & $18(10.6)$ & \\
\hline \multicolumn{5}{|l|}{ Gender } \\
\hline Male & $310(51.5)$ & $231(53.5)$ & $79(46.5)$ & \multirow[t]{2}{*}{0.01} \\
\hline Female & $292(48.5)$ & $201(46.5)$ & $91(53.5)$ & \\
\hline \multicolumn{5}{|l|}{ Ethnic group } \\
\hline Han Chinese & $359(59.6)$ & $227(52.5)$ & $132(77.6)$ & \multirow[t]{2}{*}{$<0.001$} \\
\hline Minorities & $243(40.4)$ & $205(47.5)$ & $38(22.4)$ & \\
\hline \multicolumn{5}{|c|}{ Working experiences as rural PCPs } \\
\hline 0-9years & $281(46.7)$ & $176(40.7)$ & $105(61.8)$ & \multirow[t]{2}{*}{$<0.001$} \\
\hline$\geq 10$ years & $321(53.3)$ & $256(59.3)$ & $65(38.2)$ & \\
\hline \multicolumn{5}{|c|}{ Number of patients seen per day } \\
\hline$\leq 19$ & $418(69.4)$ & $353(81.7)$ & $65(38.2)$ & \multirow[t]{2}{*}{$<0.001$} \\
\hline$\geq 20$ & $184(30.6)$ & $79(18.3)$ & $105(61.8)$ & \\
\hline
\end{tabular}

Data are presented as $\mathrm{n}(\%)$ or mean (SE) where appropriate. Chi-square tests or independent $t$-tests, where appropriate, were used to compare differences in age distribution, sex, ethnic group, working experiences, and number of patients seen per day between primary care physicians according to education level

$P$ values larger than 0.01 were rounded to two decimal places

2 diabetes) of follow-up care were delivered in clinicbased consultation rooms only (Table 2).

\section{Physician's perception of healthcare needs in follow-up care and routine practice}

A significantly higher proportion of rural PCPs who recognised greater healthcare needs was observed among those having undergraduate education level or above when compared to their counterparts who had lower education level. These self-perceived healthcare needs included the monitoring of disease complications $(83.7 \%$ vs $65.7 \% ; p<0.001)$, tracking of medication-taking behaviours $(71.5 \%$ vs $56.1 \% ; p<0.001)$, and tailored advice given on self-management $(66.7 \%$ vs $61.2 \%$; $p=0.04)$ in

Table 2 Provision of community-based follow-up care for hypertension and diabetes

\begin{tabular}{|c|c|c|}
\hline Variables & $\mathbf{N}$ & $\%(95 \% \mathrm{Cl})$ \\
\hline \multicolumn{3}{|c|}{ Provision of follow-up care for patients with hypertension } \\
\hline \multicolumn{3}{|l|}{ Frequency of care delivery } \\
\hline Less than 4 times per year & 112 & 18.7 (12.3 to 27.3$)$ \\
\hline 4 times or above per year & 490 & 81.3 (72.7 to 87.7$)$ \\
\hline \multicolumn{3}{|l|}{ Venue of care delivery } \\
\hline Clinic-based consultation rooms only & 106 & 17.6 (12.8 to 23.6) \\
\hline Mixed clinic-based consultations and home visits & 496 & $82.4(76.4$ to 87.2$)$ \\
\hline \multicolumn{3}{|c|}{ Provision of follow-up care for patients with type 2 diabetes } \\
\hline \multicolumn{3}{|c|}{ Frequency of care delivery } \\
\hline Less than 4 times per year & 130 & 21.6 (15.5 to 29.3) \\
\hline 4 times or above per year & 472 & 78.4 (70.7 to 84.5$)$ \\
\hline \multicolumn{3}{|l|}{ Venue of care delivery } \\
\hline Clinic-based consultation rooms only & 110 & 18.3 (13.6 to 24.2$)$ \\
\hline Mixed clinic-based consultations and home visits & 492 & 81.7 (75.8 to 86.4$)$ \\
\hline
\end{tabular}

Cl confidence interval 
follow-up care (Fig. 1). In routine primary care practice, however, rural PCPs with higher education level tended to report less delivery of community-based activities, in particular health promotion and education programmes $(65.5 \%$ vs $74.7 \% ; p=0.01)$ to manage hypertension and type 2 diabetes when compared to those with lower education level (Fig. 2).

\section{Physician-level factors associated with target non-attainment in the follow-up care delivery}

Rural PCPs with undergraduate education level or above (adjusted odds ratio $[\mathrm{aOR}]=1.52, p=0.049$ for hypertension; $\mathrm{aOR}=2.23, p=0.001$ for type 2 diabetes), having higher volume of patients seen per day $(\mathrm{aOR}=4.23$, $p=0.001$ for hypertension; $\mathrm{aOR}=2.33, p=0.02$ for type 2 diabetes), and who did not perform home visits as part of the service delivery $(\mathrm{aOR}=4.13, p=0.002$ for hypertension; $\mathrm{aOR}=3.20, p=0.01$ for type 2 diabetes) were more prone to be at risk for non-attainment of the target frequency of follow-up care delivery. Physicians with shorter lengths of time spent in rural primary care tended to practice less frequent follow-up care for type 2 diabetes $(\mathrm{aOR}=1.75, p=0.03)$, whilst such association was not significant for hypertension management (Table 3).

\section{Discussion}

\section{Main findings}

We found that according to this self-administered survey, around one fifth of PCPs in rural practices were unable to achieve a target frequency of 4 times per year for hypertensive and type 2 diabetic follow-up care delivery. When compared to village physicians with lower education level, those with higher education level perceived greater healthcare needs for follow-up care, but reported less community-based service delivery. Higher education level, increased daily patient volume, and no provision of home visits were physician-level risk factors associated with non-attainment of the target frequency of follow-up care for both conditions. In addition, village physicians with less working experiences tended to have less frequent follow-up care delivery in the diabetes management.

\section{Relationship with other studies}

Follow-up care is of great importance to the management of long-term conditions such as hypertension and diabetes as patients often require ongoing treatment and continuous care. Nearly $40 \%$ of the total Chinese population live in rural areas as of 2018, accounting for the second largest proportion of the rural population of the

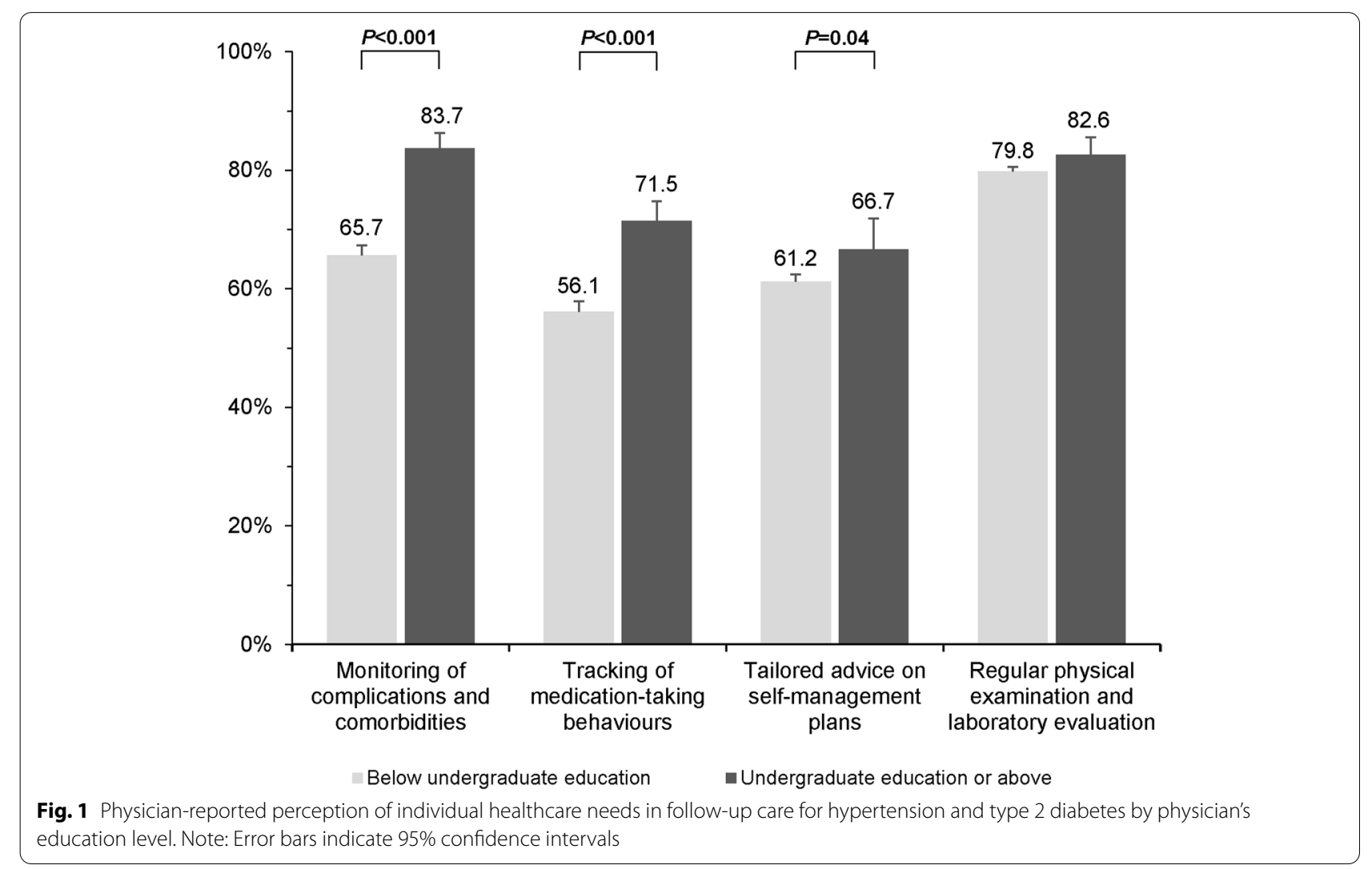




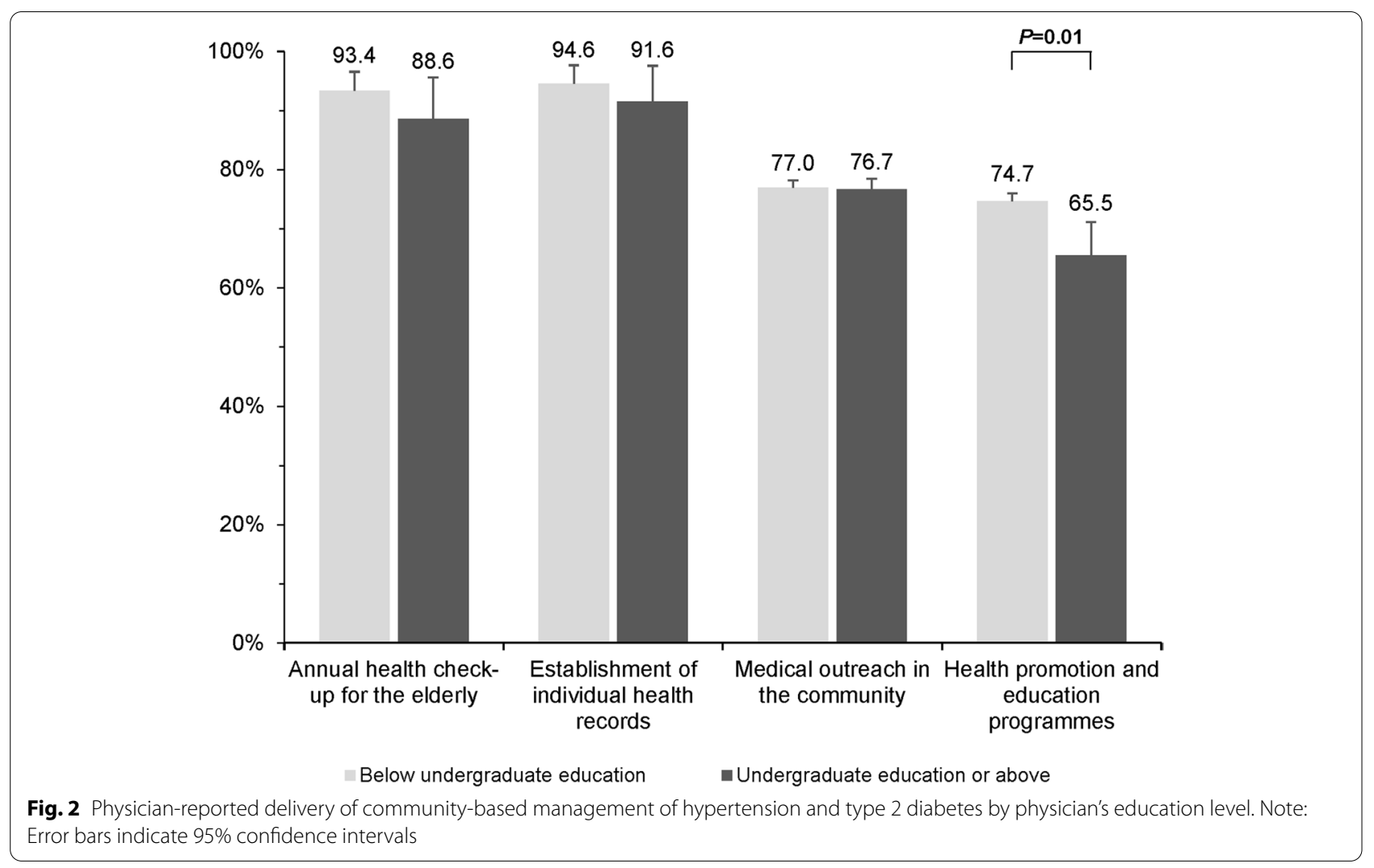

world [23]. However, the growing rural-urban health inequalities have been documented in both developed and developing countries [24, 25]. People living in more deprived rural areas tend to face greater challenges from poor accessibility of healthcare services and suboptimal physician capacity than that in more urbanised regions as a result of the 'inverse care law' [26-28]. International experience has suggested an important role of village physicians in the delivery of community-based healthcare services as the major primary care provider in rural areas [29].

We found that more than two thirds of rural PCPs participated in the study did not have an undergraduate education, which is consistent with other studies [30-33]. While patient education has played a role in achieving better BP and glycaemic control [16, 17, 34], a lack of physician's continuing medical training is one of the notable barriers to enhance capacity building. Previous research has raised concerns over the poor availability of qualified healthcare professionals in rural areas and the physician's inherent pursuit of working opportunities in urban areas given the advanced medical technology, higher remuneration and better career prospect [35]. This may be particularly common among the ethnic minorities who often reside in more remote areas with relatively poor medical resources and high illiteracy rates $[36,37]$, and village physicians of this group were therefore less likely to achieve a target frequency of 4 times per year for follow-up care for hypertension and type 2 diabetes as shown in our study.

Previous documents have reported the inability or failure of physicians to initiate or intensify therapy when a more aggressive course is recommended by guidelines, known as 'clinical inertia' in routine practice [38]. This could exist in all stages of disease management, including the beginning of lifestyle changes and strengthening of treatment [39]. Interestingly, our findings showed a positive correlation between physician's higher education level and perceived greater healthcare needs in follow-up care, which may be a result of proper knowledge and understanding of best practice acquired from better education. Nevertheless, the opposite was also illustrated in the correlation of physician's education with self-reported care delivery in routine practice, implying that better education itself may not directly translate into strong motivation and active commitment to primary care service provision. One possible interpretation is that upon the completion of higher education, village physicians may envisage more professional autonomy such as clinical work freedom [40], thus practicing less 
Table 3 Logistic regression on physician-level factors associated with non-attainment of the target frequency of follow-up care delivery

\begin{tabular}{|c|c|c|c|c|}
\hline & \multicolumn{2}{|l|}{ Model 1† } & \multicolumn{2}{|l|}{ Model $2 \ddagger$} \\
\hline & aOR $(95 \% \mathrm{Cl})$ & $P$ & aOR $(95 \% \mathrm{Cl})$ & $P$ \\
\hline Age, mean & $1.00(0.96,1.04)$ & 0.98 & $1.00(0.97,1.03)$ & 0.89 \\
\hline \multicolumn{5}{|l|}{ Gender } \\
\hline Male & 1.00 (Ref) & & 1.00 (Ref) & \\
\hline Female & $1.10(0.84,1.44)$ & 0.43 & $1.14(0.80,1.62)$ & 0.43 \\
\hline \multicolumn{5}{|l|}{ Ethnic group } \\
\hline Minorities & 1.00 (Ref) & & 1.00 (Ref) & \\
\hline Han Chinese & $0.16(0.10,0.25)$ & $<0.001$ & $0.57(0.40,0.81)$ & 0.01 \\
\hline \multicolumn{5}{|l|}{ Education level } \\
\hline Below undergraduate & 1.00 (Ref) & & 1.00 (Ref) & \\
\hline Undergraduate or above & $1.52(1.01,2.29)$ & 0.05 & $2.23(1.55,3.19)$ & 0.001 \\
\hline \multicolumn{5}{|l|}{ Working experiences } \\
\hline$\geq 10$ years & 1.00 (Ref) & & 1.00 (Ref) & \\
\hline $0-9$ years & $1.67(0.87,3.20)$ & 0.11 & $1.75(1.09,2.81)$ & 0.03 \\
\hline \multicolumn{5}{|l|}{ Number of daily patients seen } \\
\hline$\leq 19$ & 1.00 (Ref) & & 1.00 (Ref) & \\
\hline$\geq 20$ & $4.23(2.19,8.16)$ & 0.001 & $2.33(1.23,4.41)$ & 0.02 \\
\hline \multicolumn{5}{|l|}{ Venue of follow-up delivery } \\
\hline Mixed clinic and home visits & 1.00 (Ref) & & 1.00 (Ref) & \\
\hline Clinic consultation rooms only & $4.13(1.99,8.58)$ & 0.002 & $3.20(1.59,6.44)$ & 0.01 \\
\hline
\end{tabular}

aOR adjusted odds ratio; $\mathrm{Cl}$ confidence interval

†Model 1: Dependent variable: frequency of follow-up care $<4$ times per year for hypertension

$\neq$ Model 2: Dependent variable: frequency of follow-up care $<4$ times per year for type 2 diabetes

$P$ values larger than 0.01 were rounded to two decimal places

community-based services although they were able to realise the greater healthcare needs for follow-up care.

The physician's adherence to recommended clinical guidelines on follow-up care delivery may also be influenced by self-perceived workload. Workload characteristics such as the number of patients seen or administrative burdens have been reported to be associated with physician's job satisfaction [30, 41, 42]. We found that village physicians with a higher volume of patients seen per day tended to have less frequent delivery of follow-up care, which were common for both hypertension and diabetes. Under the circumstances of increased clinic-based workload, the delivery of community-based continuous care could be shrunk as a result of physician burnout [43]. The reduced initiative and motivation due to additional workload may also explain the significant association between shorter lengths of working experiences and less frequent care delivery particularly in the follow-up care for diabetes. The blood glucose test for diagnosis and monitoring requires a blood-taking procedure, which may cause extra workload on top of the blood pressure measurement perceived by junior rural physicians who have not yet achieved clinical proficiency of handling complex encounters. This may warrant further qualitative investigations to determine the extent to which self-perceived workload impacts on daily practice among village physicians of this group.

Our results suggested that the delivery of home visits as part of follow-up care also played a role. It is believed that home visits can strengthen patient-physician relationship and help physicians understand patient's culture and preferences, adding knowledge and insights to GP profession [44]. A home visit on top of routine care delivered at clinic consultation rooms is more likely to reach patients who are busy during office hour or those with disabilities, and thus physicians are more prone to achieve the recommended goal of follow-up frequency. This echoes existing literature on patient-reported barriers to routine follow-up care for hypertension and diabetes in low-income settings, including but not limited to transportation, financial burden and schedule conflicts, along with treatment adherence and satisfaction $[45,46]$. Besides, it has been suggested that therapeutic-related factors could also be related with achieving optimal practices in disease management on top of health education $[16,17,34]$. For instance, combined anti-hypertensive 
treatment was found to be superior to treatment with single drug in achieving BP goals in subjects with hypertension [47]. Recent evidence shows that advanced tele-monitoring techniques such as home-based blood pressure monitoring are capable of improving medication compliance and reducing blood pressure, with minimum additional workload for physicians [48, 49]. This could offer novel options for promoting disease management at home on top of conventional approaches to address barriers to follow-up care, and thus broaden the scope of primary care practice to accommodate healthcare needs of the local community.

\section{Strengths and weakness of the study}

Follow-up care is crucial for community-based hypertension and type 2 diabetes management particularly in lowresource settings, yet few studies have been conducted from the perspective of village physicians. We collected data from rural PCPs including ethnic minorities with a variety of geographic locations in southern, western and central China to increase the diversity of study subjects. A focus was placed on community-based follow-up care for the two conditions that are most prevalent health problems both nationally and globally. A Complex Sample design was accounted for in the analysis to improve statistically valid inferences. However, our results should be interpreted with caution. Firstly, as primary care providers are geographically dispersed across the vast expanse of rural areas, it is less feasible to visit each GP clinic for subject recruitment. Instead, study participants were approached in the setting of centralised inclass sessions where village physicians came to attend for continuing medical education through existing GP course programmes. As those who did not enrol in such programmes during the study period were not captured, it may affect the generalisability of our findings to the entire village physicians in China. Secondly, the reliance on physician's self-report of follow-up care delivery may subject to recall bias due to the absence of available data retrieved from electronic health record system. Thirdly, confounders potentially associated with care delivery such as job satisfaction may not be fully adjusted for in this study, and a physician self-report survey will inevitably restrict inclusion of questions relating to individual characteristics at patient-level. Accordingly, we were unable to differentiate whether patients aren't coming back out of their own volition versus because of the provider, despite the possibility that patient-level barriers such as transportation, financial burden and schedule conflicts might play a role $[45,46]$. Fourthly, factors associated with target non-attainment in this study may not directly indicate its correlation with patient outcomes, and the use of a specific health-status measurement as the primary outcome from the patient's perspective is warranted in future studies. Last but not least, a causeand-effect relationship could not be established given the cross-sectional nature of the study. Future large-scale studies shall extend the coverage of study subjects to a wider group of rural PCPs and service users with the assistance of internet-based, longitudinal data collection based on computerised health record.

\section{Implications for clinical practice}

Our findings could increase the understanding of followup care delivery among rural PCPs and inform areas for capacity building programmes targeted village physicians in rural primary care practice. It is worthy of note that patients who are at high risk of cardiovascular events may need more intensive follow-up care, and therefore the hindering factors identified in our study for achieving the recommended goal frequency of follow-up care may bear greater primary care challenges $[50,51]$. International evidence has suggested that increased annual number of primary care visits could be associated with increased likelihood of improved longitudinal health outcomes, and may be related with less hospital admissions and decreased healthcare costs [52-54]. Efforts that are solely devoted to enhancing rural physicians' education may not suffice for chronic care management given the possible co-existence of clinical inertia and workloadrelated factors. A mixed clinic and home visits is recommended for follow-up care delivery; nevertheless, this would inevitably require computer-aided telehealth capabilities, clinical decision-support tools and infrastructure support in the context of rural health-care resources. A recent real-world trial conducted at the county setting reported the effectiveness of a healthcare intervention comprising education and feedback for PCPs through an electronic decision support system in overcoming clinical inertia [55]. From a service delivery perspective, the barriers (or facilitators) such as service sites, the training of PCPs, clinical capabilities and physician involvement should be incorporated in the formulation of evidencebased health care strategies intended to optimise the implementation of clinical practice recommendations in rural areas with resource limitations.

\section{Conclusions}

Physician-level factors were associated with the routine delivery of community-based, follow-up care for hypertension and type 2 diabetes in rural primary care settings in China. Physicians with higher education level perceived greater healthcare needs for follow-up care; however, they reported less delivery of community-based disease management activities. Higher education level, increased daily patient volume, and no provision of home 
visits served as risk factors associated with non-attainment of the target frequency of follow-up care for both hypertension and type 2 diabetes. Rural primary care physicians with these risk factors should be given particular attention in future GP development programmes to scale-up capacities in managing long-term conditions in rural areas.

\section{Acknowledgements}

We wish to thank the course instructors, class teaching assistants, and frontline staff who participated in this study for their kind support in data collection and on-site coordination. We thank the support of the Chinese General Practice Young Professionals Alliance, in which HHXW leads the research stream, for their close liaison with the in-class course teaching sites in Yunnan, Guizhou, and Henan provinces. We also thank the Guangdong-provincial Primary Healthcare Association for their close liaison with the in-class course teaching sites in Guangdong province.

\section{Authors' contributions}

HHXW, YW, and XJH conceived the idea of the study. HHXW, HYD, YC, and YTL participated in the data collection and coordination. $Y W$ and $\mathrm{XJH}$ conducted data analysis. YW, XJH, HHXW, YTL, JJW, and SWM contributed to the literature search and interpretation of the data. $\mathrm{HHXW}, \mathrm{YW}$, and $\mathrm{XJH}$ wrote the first draft. All authors (YW, XJH, HHXW, HYD, YC, YTL, ZLL, XL, JJW, and SWM) have read, contributed to, and approved the final version of the manuscript.

\section{Funding}

National Natural Science Foundation of China (grants 71904212 and 71673309); Science and Technology Development Fund of Guangdong Province (grant 2016A020216006); Special Support Program of Guangdong Province (grant 2017TQ04R749); Basic and Applied Basic Research Foundation of Guangdong Province (grant 2019A1515011381); and National Natural Science Foundation of China (grant 72061137002) in collaboration with UK Research and Innovation (UKRI) — the Economic and Social Research Council (ESRC) and the Medical Research Council (MRC), UK (grant ES/T014164/1). The funders had no role in study design, data collection, data analysis, data interpretation, or writing of the report.

\section{Availability of data and materials}

The data that support the findings of this study are available from the corresponding author upon reasonable request.

\section{Declarations}

\section{Ethics approval and consent to participate}

Informed consent was obtained from all participants in the study. Data anonymisation was performed by removing subject identifiers from the dataset prior to data analysis. Ethics approval was granted from the School of Public Health Biomedical Research Ethics Review Committee at Sun Yat-Sen University (Ref: SYSUSPH2019032) in accordance with the Declaration of Helsinki 2013.

\section{Consent for publication}

Not applicable.

\section{Competing interests}

We declare no competing interests.

\footnotetext{
Author details

${ }^{1}$ School of Public Health, Sun Yat-Sen University, No.74 Zhongshan Road 2, Guangzhou 510080, People's Republic of China. ${ }^{2}$ The Center for Disease Control and Prevention of Zhejiang Province, Hangzhou, People's Republic of China. ${ }^{3} \mathrm{JC}$ School of Public Health and Primary Care, Faculty of Medicine, The Chinese University of Hong Kong, Shatin, Hong Kong SAR. ${ }^{4}$ Department of General Practice, Henan Provincial People's Hospital, Zhengzhou, People's Republic of China. ${ }^{5}$ School of Public Health, Kunming Medical University, Kunming, People's Republic of China. ${ }^{6}$ State Key Laboratory of Ophthalmology, Zhongshan Ophthalmic Center, Sun Yat-Sen University, Guangzhou,
}

People's Republic of China. ${ }^{7}$ Office of Cancer Screening, National Cancer Center/National Clinical Research Center for Cancer/Cancer Hospital, Chinese Academy of Medical Sciences and Peking Union Medical College, Beijing, People's Republic of China. ${ }^{8}$ Zhongshan School of Medicine, Sun Yat-Sen University, Guangzhou, People's Republic of China. ${ }^{9}$ Guangdong-Provincial Primary Healthcare Association, Guangdong, People's Republic of China. ${ }^{10} \mathrm{~S}$ chool of Public Health, Guangzhou Medical University, Guangzhou, People's Republic of China. ${ }^{11}$ Centre for Population Health Sciences, Usher Institute, University of Edinburgh, Edinburgh, Scotland, UK.

Received: 25 March 2021 Accepted: 12 October 2021

Published online: 13 November 2021

\section{References}

1. GBD 2017 Risk Factor Collaborators. Global, regional, and national comparative risk assessment of 84 behavioural, environmental and occupational, and metabolic risks or clusters of risks for 195 countries and territories, 1990-2017: a systematic analysis for the Global Burden of Disease Study 2017. Lancet. 2018;392(10159):1923-94.

2. GBD 2017 Causes of Death Collaborators. Global, regional, and national age-sex-specific mortality for 282 causes of death in 195 countries and territories, 1980-2017: a systematic analysis for the Global Burden of Disease Study 2017. Lancet. 2018;392(10159):1736-88.

3. Clark A, Jit M, Warren-Gash C, Guthrie B, Wang HHX, Mercer SW, et al. Global, regional, and national estimates of the population at increased risk of severe COVID-19 due to underlying health conditions in 2020: a modelling study. Lancet Glob Health. 2020;8(8):e1003-17.

4. Mills KT, Stefanescu A, He J. The global epidemiology of hypertension. Nat Rev Nephrol. 2020;16(4):223-37.

5. NCD Risk Factor Collaboration (NCD-RisC). Worldwide trends in blood pressure from 1975 to 2015: a pooled analysis of 1479 populationbased measurement studies with 19.1 million participants. Lancet. 2017:389(10064):37-55.

6. Manne-Goehler J, Geldsetzer P, Agoudavi K, Andall-Brereton G, Aryal KK, Bicaba BW, et al. Health system performance for people with diabetes in 28 low- and middle-income countries: a cross-sectional study of nationally representative surveys. PLoS Med. 2019;16(3):e1002751.

7. Bragg F, Holmes MV, lona A, Guo Y, Du HD, Chen YP, et al. Association between diabetes and cause-specific mortality in rural and urban areas of China. JAMA. 2017;317(3):280-9.

8. Wang ZW, Chen Z, Zhang LF, Wang X, Hao G, Zhang ZG, et al. Status of hypertension in China: results from the China hypertension survey, 20122015. Circulation. 2018;137(22):2344-56.

9. Li YZ, Teng D, Shi XG, Qin GJ, Qin YF, Quan HB, et al. Prevalence of diabetes recorded in mainland China using 2018 diagnostic criteria from the American Diabetes Association: national cross sectional study. BMJ. 2020;369:m997.

10. Wang HHX, Mercer SW. Perspective from China. In: Watt GCM, editor. The Exceptional Potential of General Practice. ISBN 978-1-7852-3158-2. London: CRC Press; 2018. p. 189-92.

11. Wang HHX, Wang JJ. Developing Primary Care in China. In: Griffiths SM, Tang JL, Yeoh EK, editors. Routledge Handbook of Global Public Health in Asia. ISBN 978-0-415-64382-5. London: Routledge; 2014. p. 584-600.

12. National Health Commission, PRC. China Health Statistics Yearbook 2019. ISBN 978-7-5679-1323-3. Beijing, PR China: Peking Union Medical College Press; 2019. p. 58.

13. National Health Commission, PRC. 2015. Introduction on National Basic Public Health Services. http://www.nhc.gov.cn/jws/tpxw/201504/49bf8 0b308fb47dbb138f86b1a49a2fc.shtml. Accessed 30 Oct 2021.

14. Demaio AR, Nielsen KK, Tersbøl BP, Kallestrup P, Meyrowitsch DW. Primary health care: a strategic framework for the prevention and control of chronic non-communicable disease. Glob Health Action. 2014;7:24504.

15. Correia JC, Lachat S, Lagger G, Chappuis F, Golay A, Beran D, et al. Interventions targeting hypertension and diabetes mellitus at community and primary healthcare level in low- and middle-income countries:a scoping review. BMC Public Health. 2019;19(1):1542.

16. Atik F, Aktas G, Kocak MZ, Erkus E, Savli H. Analysis of the factors related to the blood pressure control in hypertension. J Coll Physicians Surg Pak. 2018;28(6):423-6. 
17. Kocak MZ, Aktas G, Erkus E, Duman TT, Atak BM, Savli H. Analysis of the type 2 diabetic patients followed in a university clinic. Konuralp Med J. 2018;10(2):198-202

18. Department of Primary Health Care, National Health Commission, PRC. 2017. Standards for National Basic Public Health Services (third edition). http://www.nhc.gov.cn/jws/s3578/201703/d20c37e23e1f4c7db7b8e25f3 4473e1b.shtml. Accessed 30 Oct 2021.

19. Russo G, Cassenote AJF, Guilloux AGA, Scheffer MC. The role of private education in the selection of primary care careers in low and middleincome countries. Findings from a representative survey of medical residents in Brazil. Hum Resour Health. 2020;18(1):11.

20. Yahata S, Takeshima T, Kenzaka T, Okayama M. Long-term impact of undergraduate community-based clinical training on community healthcare practice in Japan: a cross-sectional study. BMC Med Educ. 2020;20(1):337.

21. Longenecker RL, Andrilla CHA, Jopson AD, Evans DV, Schmitz D, Larson $\mathrm{EH}$, et al. Pipelines to pathways: medical school commitment to producing a rural workforce. J Rural Health. 2021;37(4):723-33.

22. Guangdong-provincial Primary Healthcare Association (GDPHA), Guangdong, PRC. 2017. Registered number 51440000MJK802455T. http:// gdjcws.org.cn/. Accessed 30 Oct 2021.

23. United Nations, Department of Economic and Social Affairs, Population Division. World Urbanization Prospects: The 2018 Revision (ST/ESA/ SER.A/420). ISBN 978-92-1-148319-2. New York: United Nations; 2019. p. 45.

24. Scheil-Adlung X. Global evidence on inequities in rural health protection: new data on rural deficits in health coverage for 174 countries. Geneva: International Labour Organization; 2015.

25. Weinhold I, Gurtner S. Understanding shortages of sufficient health care in rural areas. Health Policy. 2014;118(2):201-14.

26. Mercer SW, Guthrie B, Furler J, Watt GCM, Hart JT. Multimorbidity and the inverse care law in primary care. BMJ. 2012;344:e4152.

27. Wang HHX, Wang JJ, Lawson KD, Wong SYS, Wong MCS, Li FJ, et al. Relationships of multimorbidity and income with hospital admissions in 3 health care systems. Ann Fam Med. 2015:13(2):164-7.

28. Mercer SW, Higgins M, Bikker AM, Fitzpatrick B, McConnachie A, Lloyd SM, et al. General practitioners' empathy and health outcomes: a prospective observational study of consultations in areas of high and low deprivation. Ann Fam Med. 2016;14(2):117-24.

29. Mohan P, Kumar R. Strengthening primary care in rural India: lessons from Indian and global evidence and experience. J Fam Med Prim Care. 2019;8(7):2169-72.

30. LiTT, Lei T, Sun F, Xie Z. Determinants of village doctors' job satisfaction under China's health sector reform: a cross-sectional mixed methods study. Int J Equity Health. 2017;16(1):64-75.

31. Shi LY, Song KM, Rane S, Sun XJ, Li H, Meng QY. Factors associated with job satisfaction by Chinese primary care providers. Prim Health Care Res Dev. 2014;15(1):46-57.

32. Zhang $X Y$, Fang $P Q$. Job satisfaction of village doctors during the new healthcare reforms in China. Aust Health Rev. 2016;40(2):225-33.

33. Skipper MT. Positive partnerships: rural communities and the primary care nurse practitioner. N C Med J. 2019;80(3):174-7.

34. Barnason S, White-Williams C, Rossi LP, Centeno M, Crabbe DL, Lee KS, et al. Evidence for therapeutic patient education interventions to promote cardiovascular patient self-management: a scientific statement for healthcare professionals from the American Heart Association. Circ Cardiovasc Qual Outcomes. 2017;10(6):e000025.

35. Yang L, Wang HM. Who will protect the health of rural residents in China if village doctors run out? Aust J Prim Health. 2019;25(2):99-103.

36. Gustafsson B, Sai D. Why is there no income gap between the Hui Muslim minority and the Han majority in rural Ningxia, China? China Q. 2014;220:968-87.

37. Huang Y, Martinez-Alvarez M, Shallcross D, Pi L, Tian F, Pan J, et al. Barriers to accessing maternal healthcare among ethnic minority women in Western China: a qualitative evidence synthesis. Health Policy Plan. 2019;34(5):384-400.

38. Phillips LS, Branch WT, Cook CB, Doyle JP, El-Kebbi IM, Gallina DL, et al. Clinical inertia. Ann Intern Med. 2001;135(9):825-34.

39. Veettil RA. Understanding clinical inertia in diabetes. J Soc Health Diab. 2019;7:77-80.

40. Salvatore D, Numerato D, Fattore G. Physicians' professional autonomy and their organizational identification with their hospital. BMC Health Serv Res. 2018;18(1):775-85.

41. Bovier PA, Perneger TV. Predictors of work satisfaction among physicians. Eur J Pub Health. 2003;13:299-305.

42. Cohidon C, Wild P, Senn N. Practice organization characteristics related to job satisfaction among general practitioners in 11 countries. Ann Fam Med. 2019;17(6):510-7

43. Ward ZD, Morgan ZJ, Peterson LE. Family physician burnout does not differ with rurality. J Rural Health. 2021;37(4):755-61.

44. Kannai R, Alon A. Advantages of home visits in family medicine. Patient Educ Couns. 2018;101(12):2243-4

45. Herskind J, Zelasko J, Bacher K, Holmes D. The outpatient management of hypertension at two sierra Leonean health centres: a mixed-method investigation of follow-up compliance and patient-reported barriers to care. Afr J Prim Health Care Fam Med. 2020;12(1):e1-7.

46. Demoz GT, Berha AB, Alebachew Woldu M, Yifter H, Shibeshi W, Engidawork E. Drug therapy problems, medication adherence and treatment satisfaction among diabetic patients on follow-up care at Tikur Anbessa specialized hospital, Addis Ababa, Ethiopia. PLoS One. 2019:14(10):e0222985.

47. Kurtkulagi O, Aktas G, Bilgin S, Meryem Atak B, Taslamacioglu Duman T, Emin DM. Combined antihypertensive treatment is better than monotherapy in hypertensive patients. Neth J Med. 2020;78(5):239-43.

48. Tang O, Foti $K$, Miller ER, Appel LJ, Juraschek SP. Factors associated with physician recommendation of home blood pressure monitoring and blood pressure in the US population. Am J Hypertens. 2020;33(9):852-9.

49. McManus RJ, Mant J, Franssen M, Nickless A, Schwartz C, Hodgkinson J, et al. Efficacy of self-monitored blood pressure, with or without telemonitoring, for titration of antihypertensive medication (TASMINH4): an unmasked randomised controlled trial. Lancet. 2018;391(10124):949-59.

50. Wang HHX, Wang JJ, Zhou ZH, Wang XW, Xu L. General practice education and training in southern China: recent development and ongoing challenges under the health care reform. Malays Fam Physician. 2013;8(3):2-10

51. Yeoh EK, Wong MCS, Wong ELY, Yam C, Poon CM, Chung RY, et al. Benefits and limitations of implementing chronic care model (CCM) in primary care programs: a systematic review. Int J Cardiol. 2018;258:279-88.

52. Anjana RM, Shanthirani CS, Unnikrishnan R, Mugilan P, Amutha A, Nair HD et al. Regularity of follow-up, glycemic burden, and risk of microvascular complications in patients with type 2 diabetes: a 9-year follow-up study. Acta Diabetol. 2015;52(3):601-9.

53. Rose AJ, Timbie JW, Setodji C, Friedberg MW, Malsberger R, Kahn KL. Primary care visit regularity and patient outcomes: an observational study. J Gen Intern Med. 2019;34(1):82-9.

54. Hostetter J, Schwarz N, Klug M, Wynne J, Basson MD. Primary care visits increase utilization of evidence-based preventative health measures. BMC Fam Pract. 2020;21(1):151.

55. Brunström M, Ng N, Dahlström J, Lindholm LH, Lönnberg G, Norberg M et al. Association of physician education and feedback on hypertension management with patient blood pressure and hypertension control. JAMA Netw Open. 2020;3(1):e1918625.

\section{Publisher's Note}

Springer Nature remains neutral with regard to jurisdictional claims in published maps and institutional affiliations. 